\title{
Case Report: Spontaneous Splenic Rupture - An Unusual Cause of Intra-abdominal Haemorrhage in Female
}

\author{
IPALAM $^{\mathrm{a}}$, MUNIRA $^{\mathrm{b}}$
}

\begin{abstract}
Summary:
Laparotomy for intra-abdominal haemorrhage due to ectopic pregnancy is a common practice in Gynaecology. But laparotomy due to nongynecological causes may rarely happen in this department. A case report is discussed here where abdomen was opened as a case of ectopic pregnancy but subsequently patient needed relaparotomy and finally diagnosed as an atraumatic splenic rupture. The purpose of
\end{abstract}

\section{Introduction:}

Intra-abdominal haemorrhage in Obstetrics and Gynaecology department is a common phenomenon. Causes are usually ectopic pregnancy, ruptured uterus or internal haemorrhage after primary surgery. It is an emergency and needs to manage urgently to save patient. In Obstetrics and Gynaecology splenic rupture not usually considered as a differential diagnosis of intra-abdominal haemorrhage and it never strike our mind to be a cause. Weidemann (1927) first defined 'spontaneous splenic rupture' as 'rupture resulting from an incident without external force'. Several underlying pathologies are associated with splenic rupture, including hematological, neoplastic, inûammatory and infectious conditions ${ }^{1}$. Spontaneous splenic ruptures(SSR) are graded as following criteria put forth by Orloff and Peskin: first, no history of trauma; second, no evidence of other organ disease ; third, no evidence of perisplenic adhesions or scarring of the spleen

a. Dr. Irin Parveen Alam, FCPS , MS (Obstetrics \& Gynaecology), Associate Prof., Dept. of Obstetrics \& Gynaecology, Sir Salimullah Medical College Mitford Hospital.

b. Dr. Sirajammunira, Assistant Surgeon, Fultala Upazila Health Complex, Khulna.

Address of Correspondence: Dr. Irin Parveen Alam, FCPS , MS (Obstetrics \& Gynaecology), Associate Prof., Dept. of Obstetrics \& Gynaecology, Sir Salimullah Medical College Mitford Hospital. Dhaka. Mobile: +88-01715348398, E-mail: dririn.alam@yahoo.com

Received: 19 Dec. 2018

Accepted: 29 Jan. 2020 this paper is to bring this differential diagnosis to clinician's minds, so that physician can consider the diagnosis of spontaneous nontraumatic splenic rupture.

Key words: Splenic rupture, intra abdominal haemorrhage (IAH)

(J Bangladesh Coll Phys Surg 2020; 38: 98-100)

DOI: https://doi.org/10.3329/jbcps.v38i2.45635

suggestive of prior trauma; and fourth, aside from hemorrhage and rupture, the spleen should be normal on gross inspection and histologic examination. In 1991 Crate and Payne added a fifth criterion that full virological studies of acute and convalescent serum should show no significant rise in antibody titers ${ }^{2}$. The diagnosis of internal haemorrhage is a clinical one, confirmed by Ultrasonography, CT scan or laparotomy. There are so many case reports on spontaneous splenic rupture but splenic rupture never mentioned as a differential of ectopic pregnancy in literature.

\section{Case report:}

A 22 -year-old P- $0+0$ married woman for 2 years presented with history of worsening lower abdominal pain, severe weakness and fatigability for one day. She had no history of missed period and she was on oral contraceptive pill. There was no history of trauma or accident. She only noticed mild fever 3-4 days back which subsided spontaneously without medication. She had no known history of hematological disorders. On examination she was moderately anemic, her pulse was 100beats/min, Blood pressure was $90 / 60 \mathrm{mmhg}$ and had abdominal tenderness which was dull and diffuses over whole abdomen with no specific radiation. She had no $\mathrm{H} / \mathrm{O}$ pervaginal bleeding. After colpo-puncture, frank blood came out. USG of whole abdomen showed there was a complex mass of about $3 / 4 \mathrm{~cm}$ in diameter at left adnexal region with free fluid in pouch of douglus, suggestive of ectopic pregnancy. Resuscitation and laparotomy by low transverse incision was done, after 
opening, abdomen was full of free blood in peritoneal cavity, both tubes were healthy and left ovary was enlarged but no definitive mass or findings of ectopic pregnancy found. There was a small tear on left ovary, it was suspected as ruptured corpus luteum. But actually this was an iatrogenic tear on ovary during handling, which was discovered later. Ovarian reconstruction was done and abdomen was closed after proper peritoneal toileting and keeping a drain. Subsequently four hours after laparotomy her vitals gradually deteriorated with features of intra-abdominal haemorrahage. Emergency relaparotomy was done but no specific point of bleeding

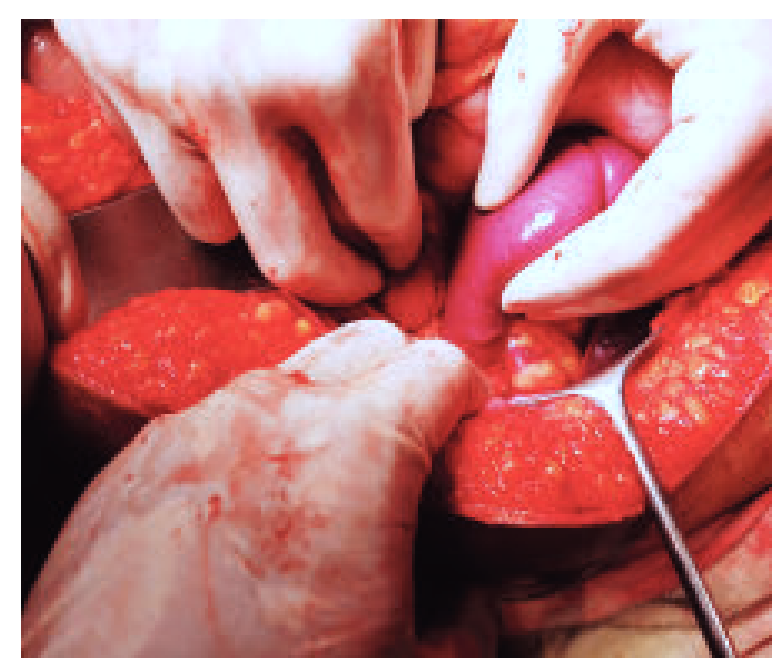

Fig.-1: Rent in spleen

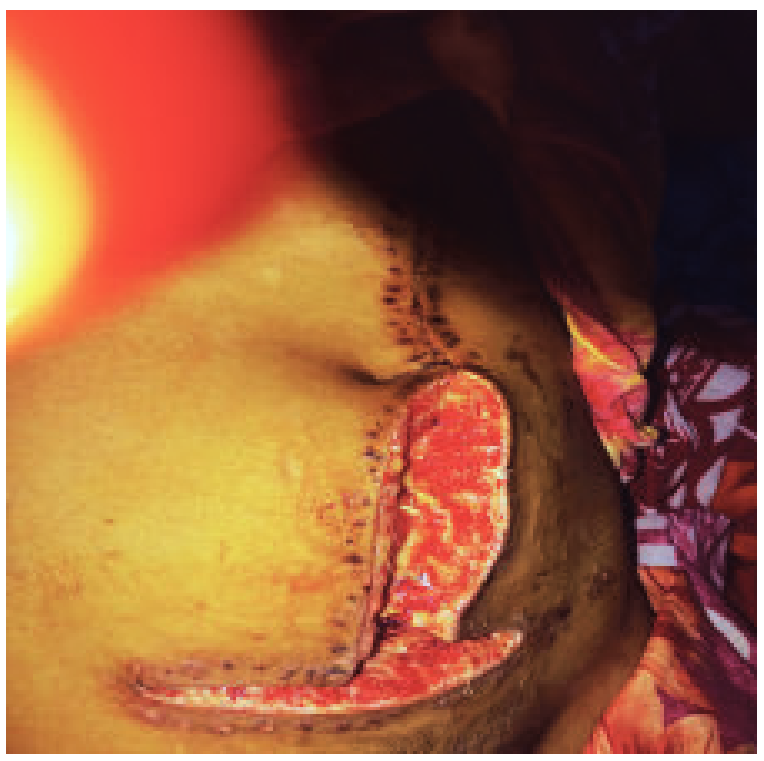

Fig.-2: On $7^{\text {th }} P O D$, Wound dehiscence was detected. Thorough peritoneal toileting with careful mopping was done. But thereafter slight progressive trickling of blood coming from upper abdomen in pelvic cavity was noticed. Surgeon was called and abdominal incision converted to vertical inverted $\mathrm{T}$ incision extending up to xiphisternum. After thorough exploration of upper abdomen nothing could be detected, but after further exploration a tiny tear was detected in the anterior border of spleen close to the notch. Rent was repaired and abdomen was closed keeping two wide bore drains one in left paracolic gutter and other in pouch of Douglas. Her $1^{\text {st }}$ postoperative day was uneventful. Later she developed high rise of fever with low blood pressure and shifted to Intensive care unit and was diagnosed as a case of septicemia. She was under multidisciplinary care and was managed under supervision of Medicine, Surgery, Hepatology, Respiratory medicine and Plastic surgery specialists. After considerable improvement of general condition, she was shifted to general ward after 2 days. But wound infection and dehiscence developed in $7^{\text {th }}$ POD both in lower transverse and vertical incision. Regular dressing was done. Subsequently she was managed under supervision of Plastic Surgery Department. After 2 months of hospital stay she was discharged with satisfactory recovery.

\section{Discussion:}

Splenic rupture is usually due to traumatic cause. But it can also occur in absence of any trauma in less than $1 \%$ of cases and usually due to previous medical diseases ${ }^{3}$. Spontaneous rupture can occur in normal spleens, but this is very rare ${ }^{4}$.

Spontaneous rupture of spleen may happen in a preexisting unnoticed mild disease ${ }^{5}$. A sudden increase in intra-abdominal pressure associated with exercise, coughing, or vomiting may produce enough strain to cause splenic capsule rupture. Minor unnoticed trauma also plays a role ${ }^{3}$. It may cause a great dilemma in diagnosis.

Spontaneous rupture of spleen may be a differential diagnosis of pancreatitis, peptic ulcer disease, myocardial infarction, pulmonary embolus, pneumonia, and nephrolithiasis ${ }^{6}$. However it was never published as a differtial diagnosis of ruptured ectopic pregnancy. It should be noted that this patient had no missed period and her ${ }^{2}$ - HCG report was normal and she was on oral contraceptive. Thus it was thought to be a case of ruptured 
corpus luteum though at that phase of menstrual cycle (premenstrual phase) this is unlikely. Patient was taken to operation table as a case of internal haemorrhage. Ultrasonographically it was diagnosed as suspected ectopic pregnancy, on laparotomy there was no bleeding from tube or adnexa. Subsequently when patient was in shock, after relaparotomy and further thorough exploration of whole abdomen, a small tear in spleen detected. Literature shows that only 1 of the 28 cases with genuinely spontaneous rupture of spleen had been correctly diagnosed preoperatively ${ }^{7}$. There are a lot of literatures reporting case reports and review articles regarding traumatic and atraumatic rupture of spleen ${ }^{8}$. The most common symptom is left upper quadrant abdominal pain, which gradually becomes generalized with abdominal distention. Tenderness and rigidity appear in later stages. Maximum patients develop haemorrhagic shock if not treated in time ${ }^{9}$.

A high index of suspicion is needed for an early diagnosis, as sometimes rupture-presenting symptoms do not differ from acute-phase symptoms or from other nonsplenic surgical emergencies. Presence of hypotension, abdominal pain, or signs of intraabdominal bleeding should alert one to the possibility of splenic rupture. In fact, if paracentesis is positive, it may be considered as a possibility of intraabdominal hemorrhage, and in a male it can be suspected as splenic rupture. In this case, culdocentesis was positive, but in a female usually it is thought to be a case of ruptured ectopic pregnancy. Abdominal ultrasonography, CT scan, and arteriography can confirm the diagnosis in a hemodynamically stable patient ${ }^{10}$. Management with early surgical intervention after hemodynamic stability is important. ${ }^{11}$ Conservative management includes: nonoperative management or splenic repair and vascular tamponade, which is the effective approach in splenic trauma with stable hemodynamics. Nonoperative management consists of bed rest in the

hospital under strict monitoring for 1 to 2 weeks with fluid and blood replacement as necessary ${ }^{12}$.

\section{Conclusion:}

Spontaneous splenic rupture is a rare entity and in a female it can cause diagnostic dilemma. It may occur even in the absence of infection, neoplastic, hematologic, or other diseases. Intra-abdominal haemorrhage in a female usually suspects an ectopic pregnancy. Though rare, but it should be kept in mind that intraabdominal haemorrhage due to splenic rupture may be a differential diagnosis of ruptured ectopic pregnancy.
Acknowledgements:

I would to like to express my very great appreciation to Prof. Muna Shalima Jahan, unit head for the case, \& for her valuable and constructive suggestions during the planning of this research article and also all Doctors and staffs of Sir Salimullah Medical College Mitford hospital, specially OBGYN and Surgery department , who were involved in the care and management of the patient.

\section{Declaration of interest}

The authors state that they have no conflicts of interest.

\section{References:}

1. H. Weaver, V. Kumar, K. Spencer, M. Maatouk, and S. Malik, "Spontaneous splenic rupture: a rare life-threatening condition; diagnosed early and managed successfully," American Journal of Case Reports, vol. 14, pp. 13-15, 2013. View at Publisher - View at Google Scholar · View at Scopus (http://www.amjcaserep.com/ fulltxt.php?ICID=883739).

2. Crate ID, Payne MJ. Is the diagnosis of spontaneous rupture of a normal spleen valid?. J R Army Med Corps. 1991;137(1):50-1.

3. Badenoch DF, Maurice HD, Gilmore OJA: Spontaneous rupture of a normal spleen. J R Coll Surg Edinb 1985; 30: $326-7$

4. Aubrey-B and Sowers BMC Emergency Medicine 2012, 12:11 http://www.biomedcentral.com/1471-227X/12/11

5. P. Renzulli, A. Hostettler, A. M. Schoepfer, B. Gloor, and D. Candinas, "Systematic review of atraumatic splenic rupture," British Journal of Surgery, vol. 96, no. 10, pp. 1114-1121, 2009.

6. CPT Timothy Laseter, MC Spontaneous Splenic Rupture, Military medicine, 169, 8:673, 2004

7. Orloff MJ, Peskin GW: Spontaneous rupture of a normal spleen. Int Abs Surg 1958; 106: 1-11

8. Ercan Gedik, Sadullah Girgin, Mustafa Aldemir, Celalettin Keles, Mehmet Cudi Tuncer, Ayfer Aktas Non-traumatic splenic rupture: Report of seven cases and review of the literature World J Gastroenterol 2008 November 21; 14(43): 6711-6716

9. Denehy T, McGrath EW, Breen JL. Splenic torsion and rupture in pregnancy. Obstet Gynecol Surv 1988; 43: 123131

10. Schackford SR, Molin M. Management of splenic injuries. Surg Clin North Am 1990; 70:595-620.

11. Bernat S, Garcia Boyero R, Guinot M, Lopez F, Gozalbo T, Canigral G. Pathologic rupture of the spleen as the initial manifestation in acute lymphoblastic leukemia. Haematologica 1998; 83: 760-761

12. Schwartz SI. Spleen. In: Schwartz SI, Shires GT, Spencer FC, Storer EH, eds. Principles of surgery. 5th Ed. New York: McGraw-Hill, 1989: 1445-1457. 